\title{
Unfolding Utilization of Functional Blocks of Social Media in Building Brand Equity in Higher Education Institutes
}

\author{
Dr. MUHAMMAD AWAIS MEHMOOD \\ Assistant Professor, Bahria Business School, Bahria University, Pakistan. \\ Email: mamehmood@bahria.edu.pk \\ Dr. QAISER RASHID JANJUA \\ Assistant Professor, Air University School of Management, \\ Air University, Pakistan. \\ Email: qaiser.jsnjus@mail.au.edu.pk; qrj786@gmail.com \\ Dr. FAISAL AFTAB \\ Associate Professor, College of Business Administration, \\ Imam Abdulrahman Bin Faisal University, Saudi Arabia. \\ Email: faaftab@iau.edu.sa
}

\begin{abstract}
The purpose of this research was to explore how HEIs are using Social Media (SM) as a marketing communication tool and to understand their branding focus through SM. It was investigated by understanding the utilization of functional blocks of SM by HEIs, which are believed to contribute towards elements of brand equity. Utilization of functional blocks of SM was studied through theoretical lens of honeycomb framework of SM. This study used qualitative methodology, based on inductive research approach. The data was collected via Netnography method, based on six months usage of SM accounts of seven selected HEIs of Pakistan, out of 225, which exhibited active SM presence. HEIs were found using nine different content types on SM. The content types that showed highest utilization of functional blocks, i.e. endorsements and promotional-messages, were amongst the least preferred content types of HEIs. However, their most preferred content types, i.e. event coverage \& announcements, showed lowest engagement level, and were seen contributing towards lower stages of brand building i.e. brand image and awareness only, thus reflecting a myopic focus of HEIs in terms of their brand building through SM. Findings of this study will enable HEIs to revisit their content preference on SM based on the desired branding objectives. This research has extended theoretical knowledge regarding SM Marketing in context of HEIs. Further, it has extended comprehension of various functional blocks of SM, in organizational context, based on literature review.
\end{abstract}

Keywords: Social Media Marketing, Brand Equity, Honeycomb Framework, Higher Education Institutes.

\section{Introduction}

Internet based technologies have reshaped the way people communicate and socialize in modern world (Chan, 2000; Wu, Yeniyurt, Kim, \& Cavusgil, 2006). This has provided a virtual form of representation to individuals and corporates, which is becoming more in use versus physical form of interaction (Leeflang, Verhoef, Dahlström, \& Freundt, 2014). Social Media (SM) is also an emergent of these technologies that are becoming more in common. Facebook alone has over 2.5 Billion users (Statista, 2020), which is more than the world's most populated country China. YouTube, LinkedIn, Twitter are functioning with 2 Billion, 675 Million \& 330 Million users respectively (Aslam, 2020). In context of Pakistan, launch of 3G/4G 
services by cellular companies, has resulted into increase in use of SM, irrespective of any social class or educational level. As per the recent statistics on SM usage in Pakistan, there are 46 Million active users, which are almost 20\% of the total population (Kemp, 2021). Almost 99\% of the users are accessing SM via mobiles. With number of mobile connections equivalent to $77 \%$ of total population, the number of SM users is expected to increase even more. It has already seen an increase of $24 \%$ in the last calendar year (2020), compared to $7 \%$ in 2019. This clearly shows the existing and future potential of this technology to reach audience at large.

The above statistics make you wonder about communication possibilities that have far superior reach versus any other form of communication, in today's fast world. In current times, a person is believed to live a more complicated and a busy life with multiple roles. Multitasking is becoming a norm, rather an option, for people to survive at any capacity. This leaves little time a person may have to spend on traditional modes of marketing communication (Aaker \& McLoughlin, 2010: 85). However SM provide firms the possibility of "communication on go" to fill in any available time slot of their customers. Higher Education Institutes (HEIs) are no different in terms of their preference of SM for communication purpose. Just like maintaining a website has become a norm across all Universities, SM presence on different platforms is also a common practice now. Almost all HEIs in Pakistan have some form of presence on SM, mainly for marketing purpose (Mehmood, Aftab, \& Mushtaq, 2016), which clearly shows the investment of time and money on part of HEIs to use it as a marketing communication tool to connect with their stakeholders. However, there is dearth of research that can reflect on these efforts to guide HEIs regarding their usage of SM technology.

Just as any other technology, SM is believed to offer various functional benefits to its users. Lack of research regarding the use of SM and its functionalities, is perhaps resulting into an oblivious approach towards utilization of this technology (Pawelz \& Elvers, 2018; Ketizmann et al., 2012). As an emerging field of research, SM platforms require more in-depth analysis to understand the full potential of its services. It will enable a better execution strategy of SM based communication for HEIs to achieve desired branding objectives. This leads to three research objectives, which are highly pivotal to learn and analyze SM usage by HEIs:

- To understand the existing execution strategy of SM based communication by HEIs, in terms of content preference.

- To analyze the engagement HEIs are able to achieve against their existing content type on SM.

- To examine the utilization of various functional blocks of SM through their execution strategy and as a result of engagement against the existing content type.

The functional blocks of SM are believed to contribute towards the constructs of brand equity (Tresna \& Wijaya, 2015) and analyzing their utilization will enable understanding branding focus of HEIs with their existing SM usage. Following research questions will guide this study:

- What are different content types being used by HEIs on their SM accounts?

- What level of engagement HEIs are able to achieve through their SM content?

- How the engagement achieved against different content type is enabling HEIs to utilize various functional blocks of SM?

\section{Literature Review}

\section{Web 2.0 and SM}

SM is a platform that is based on the Web 2.0 technologies. The term Web 2.0 was first coined in 2004 in a conference brain storming session between O'Reilly \& Media Live International where the Vice President of O'Reilly Media highlighted the changing nature of the web and its related technologies 
(O'Reilly, 2005). The web sites or applications were no longer seen as static pages of information but more dynamic with user friendly content. While the history of online based communications is as long as the advent of internet, or even before (Edosomwan, Prakasan, Kouame, Watson, \& Seymour, 2011), but communication based on Web 2.0 technologies is more instant and real-time with freedom of multiple options of sharing content such as videos, images, text and sound. There are different types of SM platforms that have emerged over the years including MySpace, Yahoo Messenger, MSN Messenger, Orkut, MySpace, Facebook, Twitter, LinkedIn, YouTube, Instagram, etc. However the framework, which support its functionalities, generally remain common with varied focus on available functionalities by various SM platforms (Kietzmann, Hermkens, McCarthy \& Silvestre, 2011). This framework, which defined the building blocks of SM, is known as honeycomb framework that is based on the work by Smith (2007). Smith's work was further evolved by Keitzmann et al. (2011) to study the implication of honeycomb framework suggesting firms how they should go about managing their SM activities. The honeycomb framework of SM is composed of seven building blocks namely identity, conversations, sharing, presence, relationships, reputation, and groups.

\section{Identity}

This building block in its basic definition can be seen as a function that enables the users of SM to disclose their identity. Some previous studies have used the presence of detailed profile on SM accounts by organizations including account name, design with logo/colors as the evidence of utilization of this building block (Senadheera, Warren, \& Leitch, 2011). But from a subjectivist view, Keitzmann, Silvestre, McCarthy and Pitt (2012) explain it as an image that is conveyed to the users through conscious or unconscious disclosure of personal identities. Identity theory acknowledges the multifaceted nature of Identity as a social construct that emerges based on several roles that are being played by people in society (Hogg, Terry \& White, 1995). The same can be implied in the context of organizations where the identity is not merely the name, logo or any demographic information, but is composition of more multifaceted social constructs, based on different roles, leading to different activities of the organization. The reflection of these activities on SM therefore can be said to contribute towards identity building where the organizations are creating an image based on what they do, where they do it and how they do it. Zhao, Grasmuck and Martin (2008) explains this identity creation on SM, specifically on Facebook, over a continuum of identity claim. On one end is the explicitly claimed identity through self explanation of one's interests and verbal description of themselves though name, profile picture, textual means or posts. On the other end is implicit identity, developed though sharing of content on wall posts, highlighting various activities, interest and hobbies aimed to generate desired image.

The utilization of this building block, from organization's perspective, can be analyzed based on the explicit efforts, which will include information shared through the profile; including account name, logo, demographic details, location, contact details (Senadheera et al, 2011), content of wall posts, tweets, etc., giving first person account of oneself but shall also embrace the content of wall posts, tweets, etc., to observe existence of information explaining lifestyle and an image to its user through implicit ways (Zhao et al, 2008).

\section{Presence}

This building block refers to the extent through which availability of users can be determined on SM networks. According to Keitzmann et al. (2012); in a virtual environment, presence has a strong positive association with people's desire to communicate. In real life, one can see that the pre-requisite of any social interaction is availability. Similarly SM interaction is not possible without the availability of those who are part of any social network. The features and actions that enable user to know availability of other on SM, allow development of trust in people to get engaged and involved in discussion to perform social interaction. 
Gunawardene (1995) defines social presence in computer aided networks as “...the degree to which a person is perceived as a "real person" in mediated communication". By quoting the Social Psychology of Telecommunication, he suggest that several options of communication media offers varied level of social presence and it is these variations that affects the manner and effectiveness through which individuals interact with each other, while using these communication media options.

Lombard \& Ditton (1997) in their quest to investigate presence, summarize the central theme of this concept as an 'illusion of non-mediation' that occurs when the people involved are not able to feel presence of any mediation in their communication. They explain this with an analogy of 'open window' where a media is perceived to allow more social interaction if it eliminates the feeling of any mediation between those at the two sides of communication medium. Imagine a person, available at all important social events or activities. Such a person will generally have more opportunities to interact, communicate and socialize compared to those who are seldom there. So a person, who is more available (presence) in SM activities, will be more connected, having more opportunities to utilize other building blocks of SM.

\section{Sharing}

Sharing block is defined as an extent to which users on SM are exchanging, receiving and distributing information online (Kietzmann, Silvestre, McCarthy, \& Pitt, 2012). The information on SM can be shared in several forms including textual data, pictures, images, videos, audio files, links, etc. Keitzmann et al (2012) explains 'sharing' from the lens of Motivation theory by Ryan and Deci (2000) where they explain two set of motivation for any activity i.e. Intrinsic and Extrinsic motivations. Intrinsic motivation is innate to the individual that encourages an individual to take actions with drive to gain personal enjoyment, selfsatisfaction, peer recognition, overcoming curiosity or sense of challenge. Whereas extrinsic motivations are related to external rewards that one eye to gain as a result of participation in some activity. In SM one could see that people are engaging with each other and sharing content based on their intrinsic and extrinsic motivations. The extent of sharing of SM content reflects its utilization.

\section{Conversation}

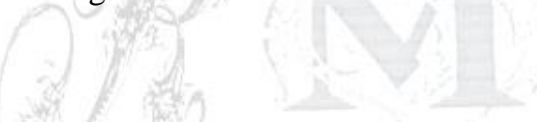

The conversation building block refers to the extent to which users on SM communicate with each other (Kietzmann et al, 2012). This is one of the key building block of several major SM network including Facebook, YouTube, Twitter, Linked, Google+, MySpace, etc. (Amalanathan \& Anouncia, 2016; Kietzmann et al , 2011). The value of many social networks, and the users of those social networks, is determined on basis of the level of conversations they are able to generate. The level of conversation in SM has been measured in previous studies on the basis of comments, mentions and replies that people would make against the posts shared by the user of any particular platform (Tresna \& Wijaya, 2015; Senadheera et al., 2011). This is one of the key building blocks that differentiate between the Web 1.0 and Web 2.0 technologies, where the earlier is reflection of static online content, mostly generated by the organizations and later is more inclined towards dynamic online content that is well supported by the amount of conversations that takes place on SM between the users.

\section{Reputation}

Reputation on SM is the extent to which users can recognize the repute of others on SM (Kietzmann et al, 2011). Kietzmann et al. (2012) also refers to reputation as a socially shaped opinion that is developed and shaped on the basis of shared opinions and experiences one would have with the brand. In order to convert these shared experiences and opinions into reputation there has to be a platform that allows exchange of these opinions and experiences through word of mouth or other means. SM is therefore considered as one of those platforms playing a strong role in shaping people's opinion about brands by developing and maintaining reputations based on these shared experiences and opinions that can easily be expressed online (Hudson \& Thal, 2013; William, Helena, Adam, Rob, \& Marina, 2017). The repute on SM is generally 
analyzed on basis of number of followers, likes, views, shares, re-tweets etc. (Keitzmann et al., 2011). These dimensions can be seen as pure quantitative means towards judging the repute of the content. But, reputation is also a highly qualitative matter and thus requires some subjective analysis. There are some advance measures, including sentiment analysis, through which SM sites are trying to analyze this qualitative information i.e. analysis of positive mentions vs negative (Kietzmann et al., 2011).

\section{Groups}

This functional block represents the extent how users can form communities and sub communities within the context of SM (Kietzmann et al, 2011). Formation of these communities in their very obvious way refer to the functionality(ies) of the SM network that allow users to form groups and subgroups to generate discussions and utilize other functional blocks of honeycomb framework. This is usually measured through quantitative ways based on social network externalities (Butler, 2001). But from a broader perspective, this functional block may also refers towards the extent to which SM users are able to gauge social interaction reflecting sign of oneness by acting in a style that is consistent across the group, conforming to the group requirements (Childers \& Rao, 1992).

This formation of communities and sub communities, under this building block, matches with the concept of brand communities that is defined as a "specialized, non-geographically bound community, based on structures set of social relations among admirers of brand" (Muniz \& O'Guinn, 2001). The formation of communities on SM can be obviously much larger in scale due to technology and can therefore be termed as special brand community with its own set of dynamics. But yet, at the same time, it is very similar to a greater extent with regular brand communities showing all the indicators including consumers' relationship with brand elements and value creation practices (Habibi, Larochea, \& Richard, 2014; Laroche, Habibi, \& Richard, 2013).

In various SM platforms there exists several ways through which users can group their conversation and people who they communicate with. Senadheera et al (2011) used the existence of 'Lists' in Twitter account as an evidence of utilization of group building block. In case of Instagram the utilization of this building block can be seen through functions like 'Instameet' that can facilitate users of SM to meet in real time and face-to-face (Tresna \& Wijaya, 2015). Hashtags, apart from their basic objective of making conversations easy to locate, is a good mode of grouping conversations for branding purposes to allow target audience easy access to information that is of their direct interest (Anderson, 2014).

\section{Relationships}

This building block refers to the extent to which users in a SM setting can relate to each other (Kietzmann et al, 2012). This building block is not attributed to SM only but to the whole concept of internet communication technologies that has long been seen as a strong tool for developing relationships through its two way communication between the organizations and customer (Taylor \& Kent, 1998). Traditionally the utilization of the relationship building block has been measured on the basis of number of fans, likes, followers, friends and subscribers one has on SM accounts (Senadheera et al., 2011; Tresna \& Wijaya, 2015). Such measures do indicate the strength of social connectivity and reach one has through their SM presence, but if only used in such absolute terms then perhaps it is better to replace the term relationship with Social Reach. Relationship building has a lot more to it than simple calculation of number of likes, fans, followers or subscribers. These aspects of relationship are termed as structural property of relationship that shows the user graphs of any SM account through the information on number of connections and the location of those connections (Kietzmann, Silvestre, McCarthy, \& Pitt, 2012). A complete reliance on this quantitative matrix may be misleading in concluding certain benefits from use of SM relationship block. The real value of SM relationship building depend less on the size of social reach and more on how one is able to draw relationship value through engagement (Barby, 2014). 
The building of this relationship value can be seen in SM setting through utilization of ties strength (weak $\&$ strong) in two ways. One is where the organization is able to gauge in positive and friendly interaction with their stakeholders (B2C). Second is where the stakeholders are involved in relationships building with each other through their presence on SM pages of the organizations (C2C) (Men \& Muralidharan, 2017; Laroche, Habibi, \& Richard, 2013; Brooker, Dutton, \& Greiffenhagen, 2017). For organizations both forms of relationship building matters to allow development of ties between all the stakeholders that positively contribute towards consumer purchase behavior (Goh, Heng, \& Lin, 2013). The value of these relationships do not depend on their level of strength as weak ties at times allow access to valuable data from informal acquaintanceship that is otherwise not available with close friends.

\section{Relationship of Functional Blocks of SM with Brand Equity}

According to Keller (1993) 'brand equity occurs when the customer is familiar with the brand and holds some favorable, strong and unique brand associations in mind'. The brand equity has mainly two dimensions; customer-based \& firm-based. From customer-based perspective brand equity is based on constructs such as brand loyalty, brand awareness, perceived quality, brand associations and other proprietary assets (Aaker, 1991: 27). Whereas from the firm-based perspective it is the incremental cash flows resulting from the brand name (Chunling, Ping, \& Haizhong, 2008).

The building blocks of SM (Keitzmann et al., 2011), apart from highlighting various functionalities, also reflect upon the benefits one may be able to accrue through their SM presence towards brand building. Previous studies in this regard have shown relationship of these functional blocks with various constructs of brand equity. Utilization of Identity \& conversation block is believed to contribute towards brand awareness; presence \& sharing block is seen to contribute towards brand image (associations); utilization of reputation block relates to perceived quality of products; group and relationship block is believed to contribute towards brand loyalty (Babac, 2011; Tresna \& Wijaya, 2015). With the recognition of contribution of SM towards brand building, it will be interesting to see, which functional blocks of SM framework are of more focus by the Pakistani HEIs. That will enable understanding the branding focus of HEIs through their SM efforts.

\section{Methodology}

This study has made use of qualitative research methodology in order to explore utilization of available functionalities of SM through the lens of honeycomb framework (Keitzmann et al., 2011). Method of netnography was used to observe 6 month's SM usage of selected HEIs. Netnography is a research method based on the concept of interpretive paradigm but specific to online marketing research to get consumer insight (Kozinets, 2002). It is arguably seen as online ethnography to research interpersonal communication on the internet (Beneito-Montagut, 2011).

In Pakistan, there are 225 universities, including mix of both private and public sector institutes. Almost all these HEIs have some form of SM presence with varied level of following. Drawing a sample from a population in a qualitative study is not from the perspective of generalizability but of in-depth exploration of an emerging phenomenon (Larkin \& Thompson, 2012). The very first step followed in this regard was to identify the universities that are considered more active and more informed regarding its efficacy as a marketing tool. It was therefore the subject Pakistani HEIs were selected across Pakistan, based on their usage of SM and the traffic they are able to attract with the use of their SM activities. This selection was carried with the purpose (purposive sampling) of exploring utilization of SM as a marketing communication tool.

In selection of most relevant HEIs, the first aspect, which was considered important, was the selection of cities from where the universities shall be picked from for the purpose of this study. The literature indicates that the cities in Pakistan with most active SM usage include Lahore, Karachi, Islamabad \& Peshawar 
(Qureshi, 2016). To enable representation of the universities from each identified SM active city, it was ensured that at least one university from these cities is included in the selected sample. The second criterion of selection, specific to universities, within the above cities was the activeness of existing SM accounts of the universities from these cities. The activeness was based on number of likes, followers or subscribers on SM accounts. Based on these two criteria, seven HEIs were selected.

From a pilot study conducted on the preference of SM networks of the subject HEIs, it was observed that they are mostly using Facebook \& Twitter. It was therefore these two platforms were selected for understanding the SM utilizations of selected Pakistani HEIs. The data was recorded in form of snapshots that were later analyzed using the research method of netnography through NVivo 11 . There were in total 3,835 snap shots of the SM usage of selected HEIs, with 2,947 snapshots of Facebook and 888 snapshots of Twitter usage.

\section{Findings}

\section{Content Types on SM (SM) of Pakistani HEIs}

The analysis of 6 months data of selected social network sites of Pakistani HEIs revealed 9 categories of content that is being placed on their SM sites including:

- Event Coverage

- Announcements

- Admissions

- Achievements

- Promotional Messages

- Endorsements

- General Knowledge

- Community Messages

- Placements

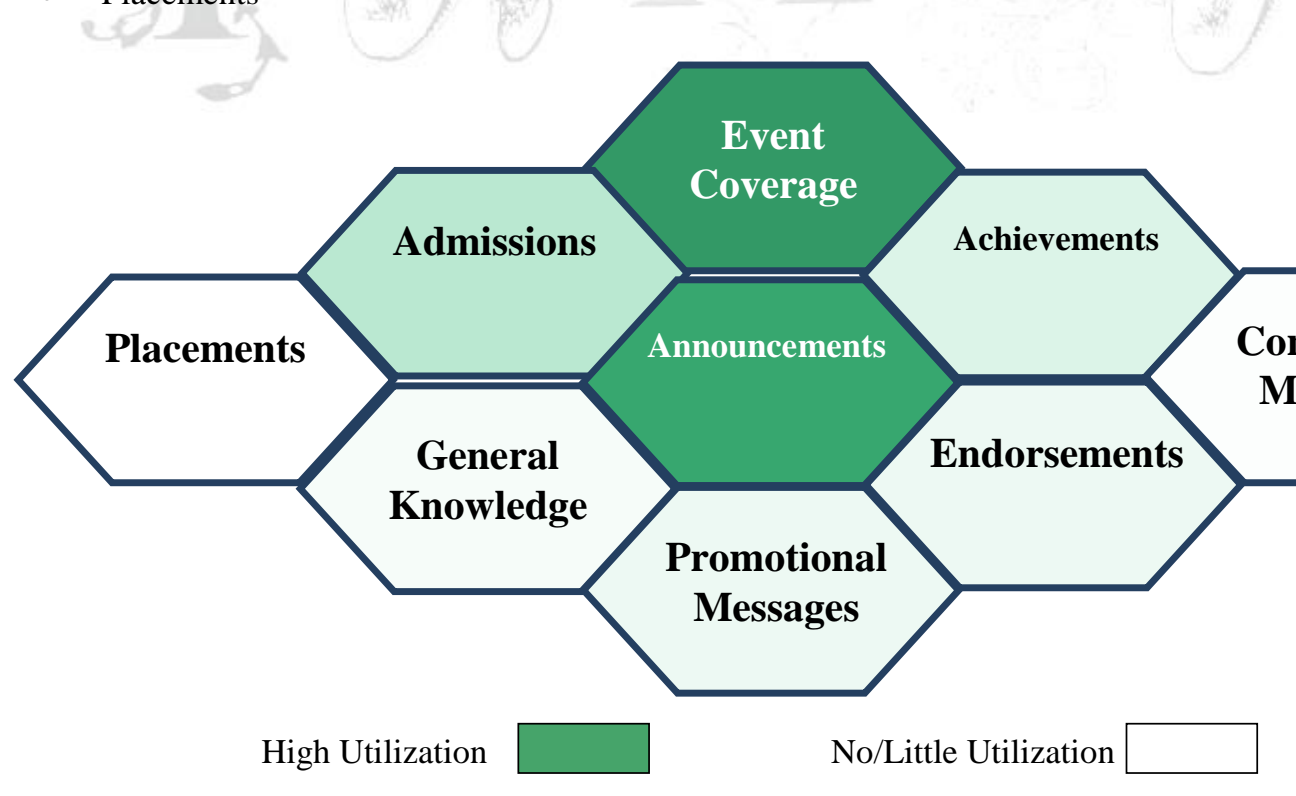

Figure 1: Utilization of various content types by selected HEIs 
'Event Coverage' was the most commonly used content type by the selected HEIs where they would be posting information about various academic and non-academic events on their SM pages.

'Announcements' category included posts that were meant mainly for communicating any official correspondence relevant for the stakeholders of the university including notices regarding leave and holidays, changes in procedures or requirements, declaration of results of examinations or selection for any academic or non-academic event.

'Admissions' posts were focusing on content related to the admissions, its criteria, procedure and information on the programmes on offer.

Posts under the category of 'Achievements' were mainly highlighting the major accomplishments of their students in academic and non-academic matters, achievements of their faculty and staff and attainment of important milestones in terms of ranking or other matters at institutional level.

Fifth category that was revealed based on the themes emerging from the netnography data was 'Promotional Messages' that included content highlighting quality of studies, facilities and faculty at the university. These were messages, which were as such not highlighting any achievements at a given time but generally conveying strengths of any particular university to promote itself to the target audience.

'Endorsements' was the sixth highest used content category that included messages by the students, faculty, staff, celebrities and people from industry endorsing the quality of academic and/or non-academic matters at the respective HEIs.

Some of the universities placed messages sharing important facts and news regarding global and local issues. Such posts were not related to any programme or services being offered by the university but were mainly posted on SM to gain the interest of audience and to share awareness about some important ongoing research, local or global matters or discovery/invention in any field. Keeping the nature of this content, it was placed under the category of 'General Knowledge'.

The eighth category that was visible in the posts of SM of the selected HEIs was 'Community Messages' that included general greetings on special occasions, posts highlighting involvement of the university in work related to development of community, condolences for any tragic incident and prayers for the community at large.

Some universities were also found using SM as a platform to share information regarding various jobs and internship opportunities. Such placement opportunities were for both internal and external hiring by potential job hunter. These posts have been placed under the category of 'Placements'.

\section{Engagement Achieved through Different Content Types:}

Different content types revealed diverse level of engagement with the target audience. This variance in engagement, while could be attributed to dissimilarity in preferences of the target audience towards a certain content type, but was also due to difference in execution of particular content type by the universities. The netnography data revealed following engagement HEIs managed to achieve, from their target audience, through their SM presence:

- Liking of content

- Sharing/Re-tweeting of content

- Views (Video Content)

- Commenting against a Content 
Comments received against various content types were analyzed through open coding scheme of netnography data followed by creation of axial nodes identifying following themes in the data:

- Students replying to student's queries

- Admissions/general queries

- Reply from HEIs against admissions/general queries

- Softening/Positive comments

- Chit-chat between friends against a post

- Feedback/suggestions

- Negative comments

The table below shows the engagement level achieved against different content types being used by HEIs in their SM communication:

Table 1: Engagement level achieved against SM content types

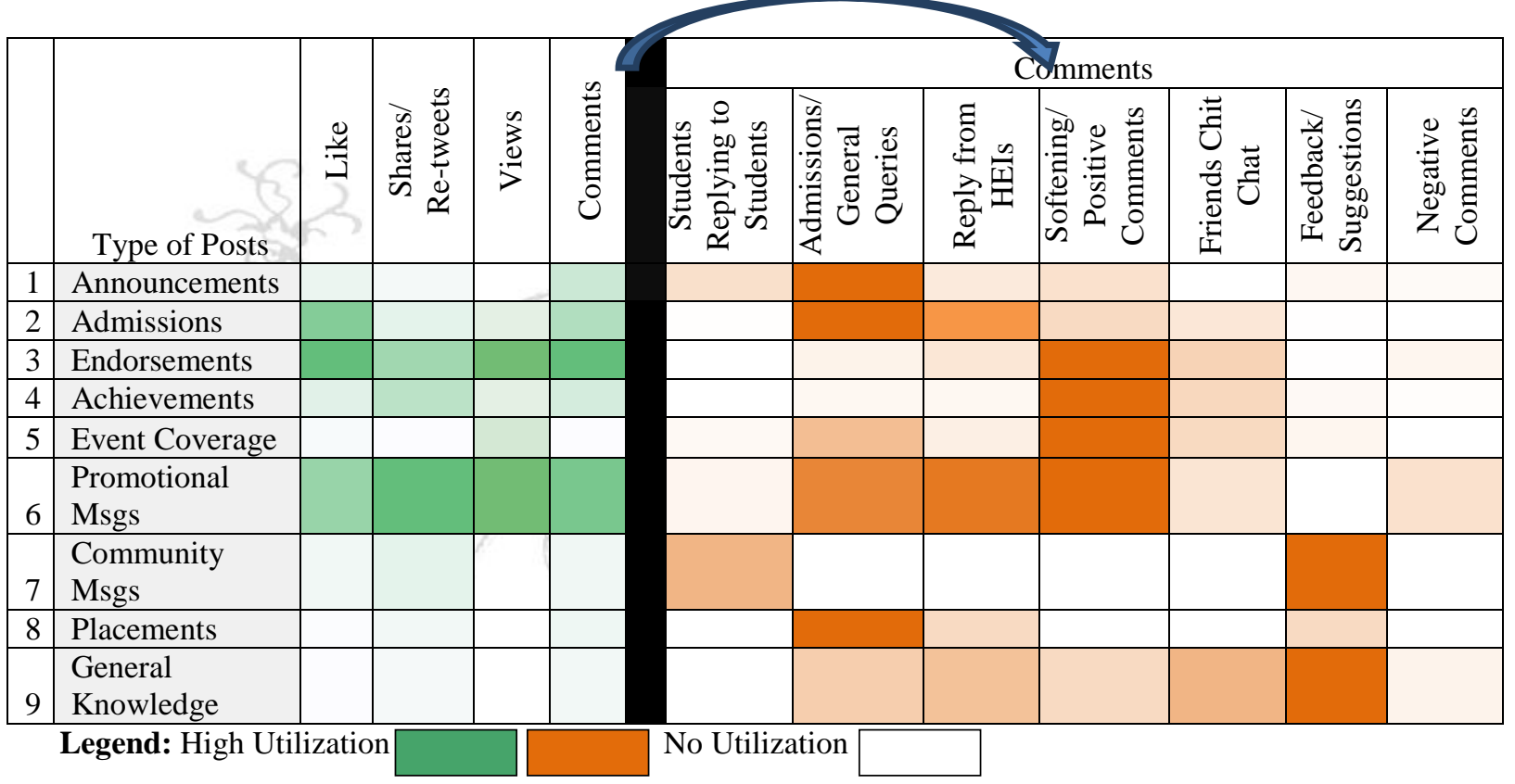

Likes

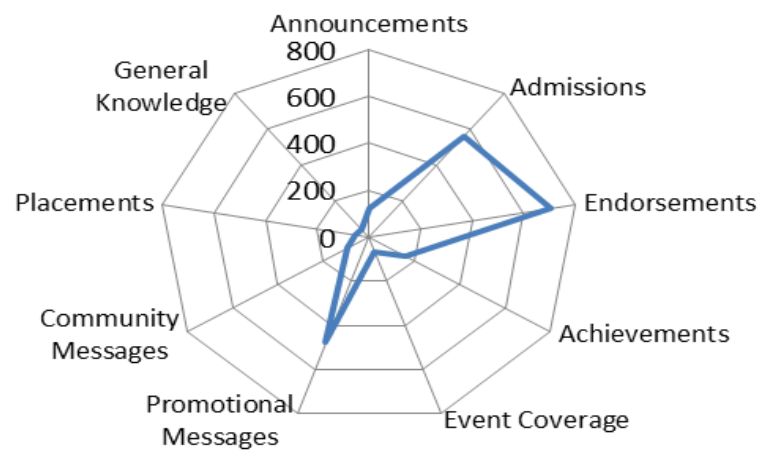

\section{Shares/ Re-tweets}

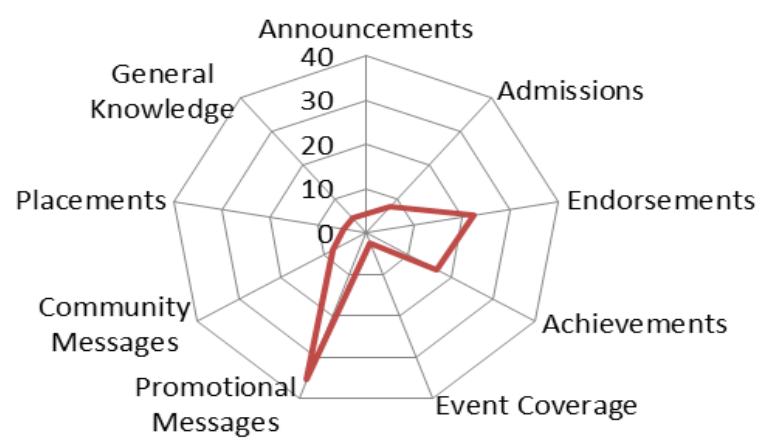



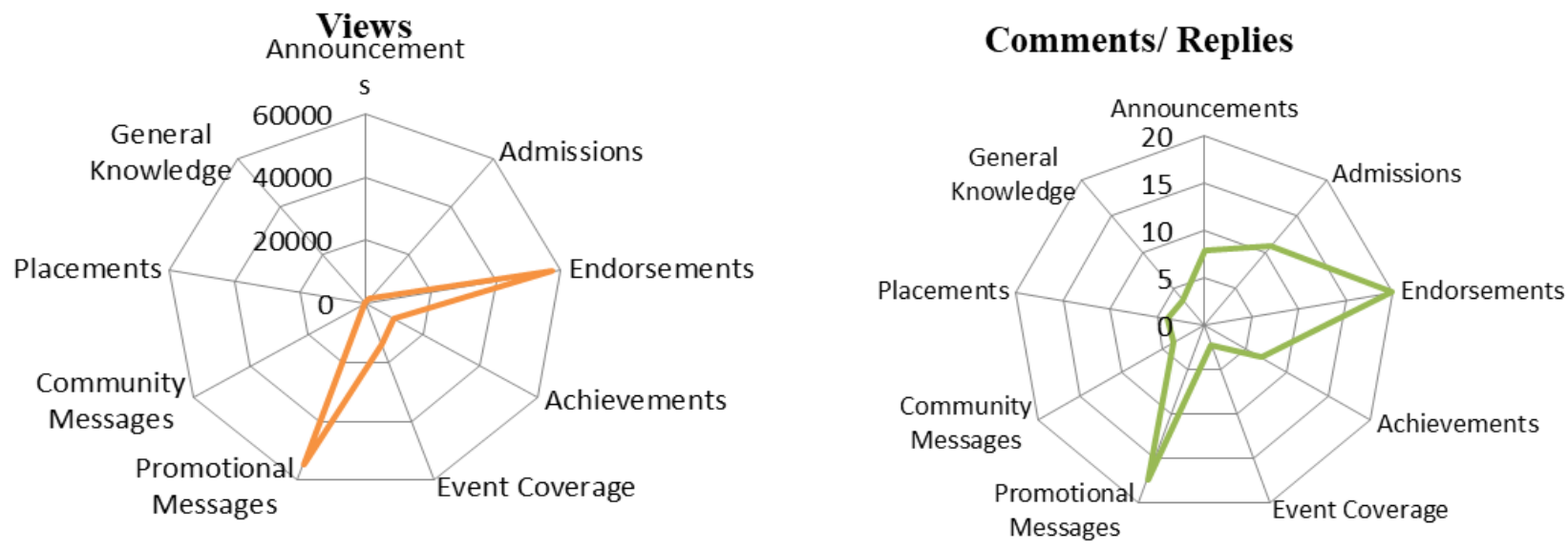

Figure 2: Engagement level achieved against SM content types (Spider Chart)

Endorsements showed the highest engagement level in terms of number of likes, comments and views. Promotional messages were the highest in terms of views and number of shares encouraging more students to share any promotional content with their friends, relatives and acquaintances. The content which is the most preferred content type by the selected HEIs, i.e. Event Coverage, is the least engaging content type out of all. The totality may shadow many important aspects pertaining to this result including the fact that video content within this category did show some promising results in terms of students' engagement, reflecting variation in engagement due to difference in execution of different content types. Also despite its low engagements level, the little communication or engagement it achieved was primarily positive and softening. Posts pertaining to Placements and General Knowledge were also low in their engagement level with respect to number of likes, shares (re-tweets) and comments.

\section{Utilization of Functional Blocks of SM across Difference Content Types}

The snapshots of the Facebook \& Twitter account of selected HEIs were analyzed using Matrix Coding functionality of NVivo 11. The first layer of coding was based on the content types, whereas second layer was based on following coding mechanism, based on the literature review above, to identify utilization of functional blocks:

Table 2: Coding mechanism followed for analyzing utilization of SM

\begin{tabular}{|l|l|}
\hline Functional Blocks of SM & Coding Mechanism adopted in NVivo 11 \\
\hline Conversation & Comments/Replies \\
\hline Sharing & Shares/Re-tweets \\
\hline Reputation (Quantitative) & No. of likes \\
\hline Reputation (Qualitative) & No. of positive mentions vs negative mentions \\
\hline Identity (Explicit) & $\begin{array}{l}\text { Posts, comments \& replies explicitly communicating features and attributes } \\
\text { of an HEI }\end{array}$ \\
\hline Identity (Implicit) & Posts, comments \& replies implicitly communicating identity of an HEI \\
\hline Presence (Firm) & $\begin{array}{l}\text { Posting of content, comments \& replies from the HEI to reflect active } \\
\text { Presence }\end{array}$ \\
\hline Presence (Users) & Posting of comments, replies, likes and sharing of the content by the users \\
\hline Relationship & $\begin{array}{l}\text { Comments \& posts reflecting relationship strengthening including gestures } \\
\text { such as courtesy, affection, love }\end{array}$ \\
\hline Group & $\begin{array}{l}\text { Comments reflecting respondent sharing feeling of belongingness to a group, } \\
\text { tribe or cline. Use of hashtag feature for grouping and connecting } \\
\text { conversation }\end{array}$ \\
\hline
\end{tabular}


The results attained from the above coding mechanism, reflecting utilization of functional blocks across different content types, are as follow:

Table 3: Utilization of functional blocks of SM across different content types

\begin{tabular}{|c|c|c|c|c|c|c|c|c|c|}
\hline Functional Blocks of SM & 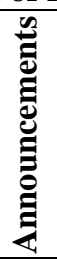 & 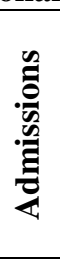 & 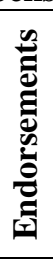 & 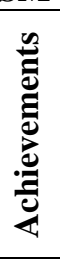 & 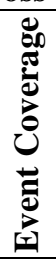 & 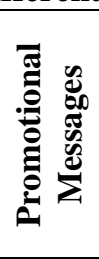 & 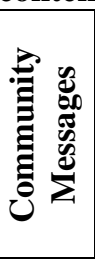 & 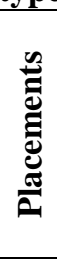 & 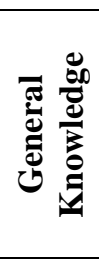 \\
\hline \multicolumn{10}{|l|}{ Conversation } \\
\hline \multicolumn{10}{|l|}{ Sharing } \\
\hline \multicolumn{10}{|l|}{ Reputation (Quantitative) } \\
\hline \multicolumn{10}{|l|}{ Reputation (Qualitative) } \\
\hline \multicolumn{10}{|l|}{ Identity (Explicit) } \\
\hline \multicolumn{10}{|l|}{ Identity (Implicit) } \\
\hline \multicolumn{10}{|l|}{ Presence (Firm) } \\
\hline \multicolumn{10}{|l|}{ Presence (Users) } \\
\hline \multicolumn{10}{|l|}{ Relationship } \\
\hline Group & & & & & & & & & \\
\hline
\end{tabular}

Legend

Netnography data revealed that posts with Endorsement and promotional messages showed the highest utilization of the conversation block, followed by Admission posts. Event coverage, which was the most extensive used content type by the HEIs, showed the lowest utilization of this functional block.

SM posts with promotional messages, endorsement and achievements showed the highest utilization of sharing functionality of SM. Posts with event coverage, announcements, placements and general knowledge were the least shared content on the SM pages of the selected HEIs.

Utilization of reputation block, gauged through quantitative means, was more visible in posts with endorsement messages, followed by admission posts and promotional messages. Event coverage, placements and general knowledge related posts reflected lowest utilization of reputation block (quantitative). Similarly, endorsement messages also showed the highest utilization of reputation block, assessed through qualitative means i.e. number of positive mentions vs negative mentions. However instead of admission posts, it was the posts highlighting university achievements and event coverage that showed highest utilization of reputation block though qualitative means.

Utilization of identity block, through explicit means, was more visible in admissions posts followed by promotional messages. However, identity development through implicit means was more visible in posts related to event coverage.

Utilization of presence block, but from firm's perspective, was more visible in Admission posts. This active presence was not only gauged on basis of number of posts against a certain content type but also on basis of active response to the queries or comments against the posts. It was seen that HEIs were generally not very responsive to the queries on SM. However, in case of admission posts, HEIs were more active and addressing the queries of students. Utilization of presence block from user's perspective, which was gauged 
on basis of active involvement and engagement of the audience against a certain content type, was more visible in endorsement messages, followed by promotional and admission posts. Event coverage, placement ads and general knowledge related posts were the least engaging posts of the selected HEIs.

Utilization of relationship and group block showed almost similar utilization level. This reflects strong interconnection between these two. Endorsement messages showed highest utilization of these two building blocks. This content type prompted conversation showing affection and strong connection with the university brand and its elements. These posts not only actively used feature of hashtag to group discussions on Facebook but also displayed content, showing element of oneness that is usually visible in case of brand communities, reflecting relationships with brand elements suggested by Habibi et al. (2014).

\section{Discussion}

The findings of the research revealed that HEIs prefer different content types on SM and managing to generate different engagement with their target audience. Students have shown varied response towards certain content. While the utilization is primarily being executed through contents such as event coverage, announcements, admissions, achievements, promotional messages, endorsement, general knowledge, community messages, and placement ads; engagement has been reflected through likes, shares/ re-tweets, views and comments. Different content types were observed to contribute towards different branding objectives. One thing that is very clear is that there exist strong efforts on part of HEIs to place content on SM to engage with their prime target audience, i.e. students, and also visible response from the student community to engage with their respective or prospective HEIs through SM. This is not at all reflection of preference of internet technologies in general, but of SM in specific, as many details available on university websites were still being enquired on SM.

Utilization of Conversation block of SM (Keitzmann et al., 2011) was more visible in posts pertaining to endorsements, promotional messages and admissions. These posts were also high in terms of their number of likes, shares (utilization of sharing block) and views. Based on the netnography results, there were apparently no visible extrinsic motivators for students to share content on SM but these post types presumably provided intrinsic motivating factors for students to share such content type with their friends, relatives and other acquaintances.

High number of positive comments has been termed as a measure of reputation on SM by Keitzmann et al. (2011) and consequently believed to contribute towards utilization of reputation block of honeycomb framework. Endorsement messages were the highest in this aspect along with promotional messages, event coverage, and post highlighting university achievements. While popularity of endorsement messages can be attributed to various factors but what seemed apparently more prominent was the fact that these posts were able to link any information with a face and a real life experience.

Previous studies have highlighted SM's ability to create identity for organizations (Zhao et al, 2008; Senadheera et al, 2011). In case of HEIs, Identity development has been visible in posts highlighting various events of the university, sharing an implicit identity (Zhao et al., 2008) to the audience. In addition endorsements also reflected higher utilization of identity block (Keitzmann et al., 2011), once again through implicit means, by letting the students speak to the audience about the university based on their personal life experiences through SM. Utilization of this building block, in its basic form, can be seen through creation of profiles by the HEIs with logo, university image, location and website address (Senadheera et al., 2011). But through the lens of identity theory (Hogg et al., 1995) that supports existence of multifaceted identities, HEIs through posting of content related to various events, achievements and endorsement messages are forming various identities that its audience can relate to, whether in form of a university that encourages sports activities, an institute that inspires entrepreneurial thought process or an HEI that encourages hands-on learning experience. 
Posts pertaining to achievement, endorsements, promotional messages \& events coverage had the strongest influence over the reputation building in terms of both quantitative (number of likes, comments, shares) and qualitative (sentiment analysis) dimensions (Keitzmann et al., 2011). Endorsement messages appeared to play a more effective role in terms of conveying the image of high repute. Relativism perhaps makes it difficult to achieve collective appreciation of any piece of information. But then SM is about reaching wider audience, with everyone having different perspectives and realities of life. A university that offers scholarships to the needy is a good act that may be considered valuable by those who can comprehend how much such scholarships mean to those who cannot afford. But for those, who have perhaps not experienced a life with limited resources, the rich class, may not be fully able to appreciate the value of such an act (i.e. scholarship). So by simply posting information on SM that an HEI offers scholarships may not add much to the reputation of that HEI, especially in the eyes of those who cannot comprehend value of financial support due to their comfortable financial background. For the same if you pick a student whose life got changed due to such scholarship and put an endorsement message on SM while laying out his/her story, it increases the probability of recognition of such an act as a good gesture on part of any HEI. Similarly, conveying information that can contribute towards utilization of reputation block of SM (Keitzmann et al., 2011), through endorsement by those who have lived and experienced the reality, perhaps increases the probability of its acceptability as a good gesture by the target audience.

Utilization of relationship building was mainly reflected in posts with endorsements messages from the students appreciating quality of education and their affiliation with the university (B2C). Endorsement messages prompted conversation showing affection and strong connection with the university brand and its elements. This ability of endorsement messages on SM shows its potential as a strong catalyst to not only project but also provoke relationship building by engaging students. Posts highlighting achievement also showed higher utilization of relationship block in similar context. The branded content in form of promotional video and pictorial messages also played an active part in relationship building by generating comments, replies and activity showing positive response towards HEIs brand. The peer relationship (C2C) suggested by Goh et al. (2013) was reflected through students' helping other students by replying to their queries on SM. This primarily was observed in content highlighting announcements and community messages. Such assistance is evidence of inter-customer service that according to Laroche et al. (2013) contribute towards development of brand trust and loyalty. Peer relationship was also evident in form of students' engagement with their friends, involving in friendly chit-chat against the posted content. Its highest reflection was in general knowledge posts where an institute may post a general knowledge question in reply to which students will jump in to the discussion along with their friends by posting their answer and views. Apart from this, posts highlighting university's events, achievement and endorsement also generated some friendly discussion between students. This was mostly prompted where students were seeing their friends on SM pages of their HEIs and tagging the content for their information. Not only was this resulting into friendly chit-chat between friends but also spreading the content to wider audience through tag feature of Facebook. This further supports the value of SM content revolving around students. Students' focused content was clearly seen helping HEIs engage them more actively with their posts and also resulting into wider spread of the information they wish to share with their target audience.

The C2C, or in case of HEIs S2S (students to students), communication on SM seems to support the development of brand communities (Muniz \& O'Guinn, 2001). According to Ketizmann et al. (2011), formation of communities and sub-communities on SM is a reflection of utilization of group functionality. Such content is believed to help HEIs convert their students' community into brand communities where people live, talk and discuss matters from the platform of a brand and group together.

Admission posts, endorsements and promotional messages were high in terms of utilization of presence functionality of honeycomb framework (Keitzmann et al., 2011). The concept of presence here was extended from its existing form suggested by Keitzmann et al. (2011) where mere information regarding availability of the user is interpreted as utilization of presence block. The concept of presence on SM, in organizational use, is apparently more than that. According to Keitzmann et al. (2012), presence is the 
extent to which users can assess presence of other users on SM. This assessment is not simply possible through status update (e.g. away, busy, online, etc.). True presence is perhaps nothing more than a feeling of non-mediation. This is possible through active involvement on part of HEIs where students can feel true presence of HEIs when they are able to see constant update of SM pages and are able to gain their response against the posted queries. Likewise students' presence can be gauged through active posting of comments, sharing, re-tweeting and liking of the posted content by them. The more actively HEIs will post content and reply to students' queries, more feeling of an 'open window' (Lombard \& Ditton, 1997) they will have in their communication. This was mainly due to Facebook account usage where the universities not only showed presence by posting contents but also by actively replying to prospective students queries regarding admissions. This conveyed an open window policy that encouraged students to interact more with the HEIs.

\section{Conclusion}

To conclude, SM is clearly seen as an emerging preferred mode of communication by HEIs in Pakistan. They are adopting a multipronged strategy of communication where various content types are being used to engage with their stakeholders. The engagement received against these different content types vary based on the way of execution of these messages and level of student's interest towards a certain content type. Endorsement and promotional messages, admission posts and posts highlighting university achievements have shown the highest utilization of various functional blocks of SM. Endorsement messages were high in terms of utilization of relationship and group block that is considered to contribute towards pinnacle of brand equity i.e. brand loyalty (Babac, 2011; Tresna \& Wijaya, 2015). However, it was not a preferred content type of the selected HEIs. These HEIs were more inclined towards using SM for post event coverage and announcements. The preferred content types showed higher utilization of identity block of honeycomb framework (Keitzmann et al., 2011). Previous researches have shown relationship of identity block with brand awareness only (Babac, 2011; Tresna \& Wijaya, 2015). If the purpose of HEIs on SM is simple brand awareness, then this execution may be justified. However, many important functionalities supported by SM, such as reputation, sharing and relationship building, which are believed to contribute towards important branding objectives i.e. brand image, perceived quality and brand loyalty (Tresna \& Wijaya, 2015), will not be optimally utilized. This is resulting into underutilization of a technology that can support higher branding objectives for any organization.

\section{References}

Aaker. (1991). Managing Brand Equity; capitalizing on the value of brand name. New York: The Free Press.

Aaker, D. A., \& McLoughlin, D. (2010). Strategic Market Management: Global Perspective. New Jersey: John Wiley \& Sons.

Amalanathan, A., \& Anouncia, S. M. (2016). A review on user influence ranking factors in social. Int. J. Web-Based Communities, 12(1), 74-83.

Anderson, A. (2014, 4 17). What is a Hashtag? Benefits of Hashtags for Business. Retrieved 12 11, 2016, from FusionFarm: http://blog.fusionfarm.com/what-is-a-hashtag-benefits-of-hashtags-for-business

Aslam, S. (2020, 7 29). Linkedin by the Numbers: Stats, Demographics \& Fun Facts. Retrieved 9 4, 2020, from Omnicore: https://www.omnicoreagency.com/linkedin-statistics/

Babac, R. (2011, 05 27). Impact of Social Media Use on Brand Equity of Magazine Brands. Dissertation in International Marketing. Halmstad, Sweden: Halmstad University.

Barby, M. (2014, 11 25). Facebook Likes Don't Matter Anymore. Retrieved 12 12, 2016, from MATTHEW BARBY: https://www.matthewbarby.com/facebook-likes-dont-matter/

Beneito-Montagut, R. (2011). Ethnography goes online: towards a user-centred methodology to research interpersonal communication on the internet. Qualitative Research, 11(6), 716-735.

Brooker, P., Dutton, W., \& Greiffenhagen, C. (2017). What would Wittgenstein say about social media? Qualitative Research, 17, 610-626. 
Butler, B. (2001). Membership size, communication activity, and sustainability: a resource-based model of online social structures. Information Systems Research, 12(4), 346-362.

Chan, S. L. (2000). Information technology in business processes. Business Process Management Journal, 6(3), 224-237.

Childers, T., \& Rao, A. (1992). The Influene of Familial and Peer-based Referent Groups on Consumer Decisions. Journal of Consumer Research, 19(2), 198-212.

Chunling, Y., Ping, Z., \& Haizhong, W. (2008). An empirical evaluation of a customer-based brand equity model and its managerial implications. Front. Business Res, 2(4), 553-570.

Edosomwan, S., Prakasan, S. K., Kouame, D., Watson, J., \& Seymour, T. (2011). The History of Social Media and its Impact on Business. The Journal of Applied Management and Entrepreneurship, 16(3), 79-91.

Goh, K.-Y., Heng, C.-S., \& Lin, Z. (2013). Social Media Brand Community and Consumer Behavior: Quantifying the Relative Impact of User- and Marketer-Generated Content. Information Systems Research, 24(1), 88-107.

Gunawardena, C. N. (1995). Social Presence Theory and Implications for Interaction and Collaborative Learning in Computer Conferences. International Jl. of Educational Telecommunications, 1(2/3), 147166.

Habibi, M. R., Larochea, M., \& Richard, M.-O. (2014). Brand communities based in social media: How unique are they? Evidence from two exemplary brand communities. International Journal of Information Management, 34, 123-132.

Hogg, M., Terry, D., \& White, K. (1995). A tale of two theories: A critical comparison of Identity theory with social identity theory. Social Psychology, 58(4), 255-269.

Hudson, S., \& Thal, K. (2013). The Impact of Social Media on the Consumer Marketing. Journal of Travel \& Tourism Marketing, 30, 156-160.

Keller. (1993). Conceptualizing, measuring, and managing customer-based brand equity. Journal of Marketing, 57(1), 1-22.

Kemp, S. (2021). Digital 2021: Pakistan. Singapore: Kepios Pte. Ltd. Retrieved May 29, 2021, from https://datareportal.com/reports/digital-2021-pakistan

Kietzmann, J. H., Hermkens, K., McCarthy, I. P., \& Silvestre, B. S. (2011). Social media? Get serious! Understanding the functional building blocks of social media. Business Horizons, Vol 54, 241-251.

Kietzmann, J. H., Silvestre, B., McCarthy, I., \& Pitt, L. (2012). Unpacking the Social Media Phenomenon: towards a research agenda. Journal of Public Affairs, 10(2), 109-119.

Kozinets, R. V. (2002). The Field Behind the Screen: Using Netnography For Marketing Research in Online Communities. Journal of Marketing Research, Vol 39 (2), 61-72.

Larkin, M., \& Thompson, A. (2012). Interpretative Phenomenological Analysis in Mental Health and Psychotherapy Research. In A. Thompson, \& D. Harper, Qualitative ResearchMethods in Mental Health and Psychotherapy: A Guide for Students and Practitioners, First Edition. (pp. 99-116). Oxford: John Wiley \& Sons, Ltd.

Laroche, M., Habibi, M. R., \& Richard, M.-O. (2013). To be or not to be in social media: How brand loyalty is affected by social media? International Journal of Information Management, 33 , 76-82.

Leeflang, P. S., Verhoef, P. C., Dahlström, P., \& Freundt, T. (2014). Challenges and solutions for marketing in a digital era. European Management Journal, 32, 1-12.

Lombard, M., \& Ditton, T. (1997). At the heart of it all: the concept of presence. Journal of ComputerMediated Communication, 3(2).

Mehmood, M. A., Aftab, F., \& Mushtaq, H. M. (2016). Role of Social Media Marketing in HEIs Admission. Journal of Business Studies, 12(2), 137-152.

Men, L. R., \& Muralidharan, S. (2017). Understanding Social Media Peer Communication and Organization-Public Relationships: Evidence From China and the United States. Journalism \& Mass Communication Quarterly, 94(1), 81-101.

Muniz, A., \& O’Guinn, T. C. (2001). Brand Community. Journal of Consumer Research, 27(4), 412-432. 
O'Reilly, T. (2005, 9 30). What Is Web 2.0: Design Patterns and Business Models for the Next Generation of Software. Retrieved 11 2, 2015, from https://www.oreilly.com/pub/a/web2/archive/what-is-web20.html

Pawelz, J., \& Elvers, P. (2018). The Digital Hood of Urban Violence: Exploring Functionalities of Social Media and Music Among Gangs. Journal of Contemporary Criminal Justice, 34(4), 442-459.

Qureshi, U. (2016, 09 27). Pakistan Facebook Users crosses the landmark of 25 Million users. Umair Qureshi.com. Pakistan. Retrieved 11 17, 2016, from http://umairqureshi.com/pakistan-deepensfacebook-user-base-with-over-11-million-users/

Ryan, R., \& Deci, E. (2000). Intrinsic and extrinsic. motivations: classic definitions and new directions, 25(1), 54-67.

Senadheera, V., Warren, M., \& Leitch, S. (2011). A Study into How Australian Banks Use Social Media. Proceedings of the 15th Pacific Asia Conference on Information Systems, (pp. 1-12). Brisbane: The University of Queensland.

Smith, G. (2007, April 4). Social Software Building Blocks. Retrieved December 30, 2015, from nform: http://nform.com/ideas/social-software-building-blocks/

Statista. (2020). Number of social network users worldwide from 2010 to 2021 (in billions). New York: Statista. Retrieved 9 2, 2020, from https://www.statista.com/statistics/264810/number-of-monthlyactive-facebook-users-worldwide/

Taylor, M., \& Kent, M. L. (1998). Building dialogic relationships through the world wide web. Public Relations Review, 24(3), 321-334.

Tresna, L., \& Wijaya, J. C. (2015). The Impact of Social Media Towards Brand Equity: An Empirical Study of Mall. iBuss Management, 3(2), 37-48.

Tresna, L., \& Wijaya, J. C. (2015). The Impact of Social Media Towards Brand Equity: An Empirical Study of Mall X. iBuss Management, 3(2), 37-48.

William, H., Helena, W., Adam, E., Rob, P., \& Marina, J. (2017). Digitizing Sacks? Approaching social media as data. Qualitative Research 17 (6), 627-644.

Wu, F., Yeniyurt, S., Kim, D., \& Cavusgil, S. T. (2006). The impact of information technology on supply chain capabilities and firm performance: A resource-based view. Industrial Marketing Management, 35(4), 493-504.

Zhao, S., Grasmuck, S., \& Martin, J. (2008). Identity Construction on Facebook: Digital empowerment in anchored relationships. Computers in Human Behavior, 24, 1816-1836. 